RELACult - Revista Latino-Americana de Estudos em Cultura e Sociedade e-ISSN 2016/Atual: 2525-7870 | e-ISSN 2015/2016: 2447-018X

\title{
O campo do patrimônio cultural da cidade de Joinville (2013- 2016): Agentes, Limites e Perfil Diagnóstico
}

O campo do patrimonial cultural de la ciudad de Joinville (2013-2016): Agentes, Limites y Perfil Diagnóstico

The field of cultural heritage of Joinville (2013-2016): Agents, Limits and Diagnostic Profile

\author{
Christiane Heloisa Kalb ${ }^{1}$ \\ Maria Bernardete Ramos Flores ${ }^{2}$
}

\begin{abstract}
Resumo
Vários discursos e narrativas foram construídos sobre o passado da cidade de Joinville nos mais de cinquenta anos de agenda patrimonial. Para este estudo realizamos um recorte temporal entre os anos de 2013 a 2016 onde analisaremos como vem se reconfigurando o campo patrimonial da cidade de Joinville. Nessa análise temos o intuito de averiguar como o campo do patrimônio vem/vinha se estruturando nessa última gestão (2013/2016) e para tanto, trazemos alguns dados numéricos para fins de comparação entre as fases das políticas públicas de preservação do patrimônio joinvillense. Esses dados foram obtidos a partir da pesquisa de Tese de Doutoramento realizada junto ao Programa Interdisciplinar em Ciências Humanas, da UFSC. A tese teve como tema principal as políticas públicas de preservação do patrimônio cultural da cidade de Joinville. Por ora, o que se conclui é que o reconhecimento dos mais diversos discursos que engendram o que é patrimônio na cidade hoje é uma realidade a pouco tempo enfrentada. Essa mudança de paradigma vem sendo sentida há pouco mais de 10 anos. Esse debate vem abrindo brechas para outros olhares sobre o passado da cidade e também novos diálogos que nem sempre foram considerados em sua totalidade.
\end{abstract}

Palavras-Chave: Campo do patrimônio, gestão, Joinville, fases políticas

\section{Resumen}

Varios discursos y narrativas se construyeron sobre la ciudad de Joinville en nuestros días de agenda patrimonial. Para este estudio realizamos una recorte temporal entre los años de 2013 y 2016, donde se muestra cómo se reconfigura en el campo patrimonial de la ciudad de Joinville. Nessa se ha traducido en el diseño del campo de la propiedad y se ha estructurado en la última gestión (2013/2016) y para tanto, se han presentado algunos datos numéricos para las líneas de resultados entre las fases de las políticas públicas de conservación del patrimonio. Esses data ont obtidos a partir de la investigación de Tese de Doutoramento realizada junto al Programa Interdisciplinar en Ciencias Humanas, de UFSC. A tese teve como tema principal como políticas públicas de preservación del patrimonio cultural de la ciudad de Joinville. Por ora, o que se concluya que el reconocimiento

\footnotetext{
${ }^{1}$ Professora Doutora - Departamento de Direito - CESUSC - Complexo de Ensino Superior de Santa Catarina. Doutora em Ciências Humanas, PPGICH, UFSC, Florianópolis-SC. Mestre em Patrimônio Cultural e Sociedade, Univille, Joinville-SC. Advogada atuante em SC. Bacharel em Direito, Univille, Joinville. E-mail: christianekalb@hotmail.com.

2 Professora titular do Departamento de História da UFSC - Universidade Federal de Santa Catarina - Campus Reitor. Graduada em História pela Universidade do Vale do Itajaí (Univali), mestre em História pela UFSC, doutora em História pela Pontifícia Universidade Católica de São Paulo (PUC/SP), Pós-Doutora pela Universidade Nova de Lisboa/University of Maryland e pela Universidad de San Martín. E-mail: mberna@gmail.com. (orientadora)
} 
de los más diversos discursos que engendram o que es un patrimonio en la ciudad actual es una realidad a poco tiempo enfrentada. Esta cambio de paradigma viene de ser sentida poco más de 10 años. Este debate se ha desarrollado para otros países que han pasado por la ciudad y también hay nuevos diálogos que no han aparecido en su totalidade.

Palabras clave: Campo do patrimônio, gestión, Joinville, fases políticas.

\begin{abstract}
Several speeches and narratives were built on the past of the city of Joinville in the more than fifty years of cultural heritage agenda. For this study we made a temporal cut between the years of 2013 to 2016, where we will analyze how the heritage field of the city of Joinville has been reconfigured. In this analysis we intend to find out how the heritage field has been structured in this last management (2013/2016) and to do so, we bring some numerical data for purposes of comparison between the phases of the public policies of preservation of the assets of Joinville. These data were obtained from the PhD thesis research carried out with the Interdisciplinary Program in Human Sciences, UFSC. The main theme of the thesis was the public policies for the preservation of the cultural heritage of the city of Joinville. For the moment, what we conclude is that the recognition of the most diverse discourses that engender what is heritage in the city today is a reality soon faced. This paradigm shift has been felt for more than 10 years. This debate has opened gaps to other glances about the city's past and also new dialogues that have not always been considered in their entirety.
\end{abstract}

Keywords: Heritage field, management, Joinville, political phases

\title{
1. Introdução
}

O patrimônio cultural da cidade de Joinville, localizada ao norte catarinense, possui legislação própria vigente e em conformidade com os estatutos estaduais e federais que visam à preservação e à conservação de seus bens culturais. É relevante, no entanto, perceber que essas normas foram sancionadas em certos períodos nos quais os discursos do campo do patrimônio estavam sendo produzidos, portanto, ungidos de estratégias narrativas e práticas politizadas relacionadas aos atores ali envolvidos.

Esses atores do campo do patrimônio de Joinville fazem/faziam parte da Comissão do Museu Nacional de Imigração e Colonização - MNIC, da Fundação Cultural de Joinville - FCJ, da Comphaan - Comissão de Patrimônio Cultural da cidade e/ou também do Conselho Municipal de Cultura, sendo que estas pessoas estavam ligadas ou não à Prefeitura Municipal. O campo do patrimônio da cidade veio sendo construído mais efetivamente a partir dos anos sessenta, quando o grupo que fundou o Museu Nacional começou a atuar também em outros patrimônios da cidade, juntamente com o Conselho Municipal de Cultura que atuava timidamente. Nos anos oitenta, a Comphaan (Joinville, 1980) e nos noventa a FCJ foram criadas e iniciaram outras agendas dentro da urbe joinvillense, agora com planos de gestão institucionalizados.

Passados mais de cinquenta anos, desde os primeiros passos em direção a uma agenda patrimonial na cidade de Joinville, o que se vê nos últimos tempos são muitos exemplares de patrimônio protegidos pelo tombamento ou pelo inventário [recentemente normatizado por lei 
complementar 363/2011] que vêm suportando as consequências da contemporaneidade: novos usos, ressignificações, mas velhos dilemas. Essas consequências ainda sufocam um resquício de ethos germânico da cidade, suplantadas pelas recriações simbólicas das múltiplas identidades de Joinville. Conforme afirma Flores (1997, p. 77), “as identidades são sempre transitórias, politicamente atribuídas e mantidas e se transformam socialmente, podendo também serem esquecidas, abandonadas ou inventadas". Nesse sentido, a criação da identidade que marca determinado local é um processo imagético dentro de propósitos que se abrem em sua própria contemporaneidade.

Joinville foi habitada por pessoas que eram, em sua maioria, de acordo com as estatísticas numéricas realizadas pelos próprios administradores da Colônia, imigrantes europeus, especialmente de origem germânica, que chegaram à cidade a partir de 1851, ano de sua fundação, vindos de países mais industrializados (COELHO, 2011; FICKER, 2008; GUEDES, 2005; NIEHUES, 2000). Alguns destes imigrantes europeus eram oriundos de famílias ricas que criaram fábricas e pequenos negócios. Outros imigrantes trabalharam como operários e trabalhadores e também fizeram parte da construção da cidade recém colonizada.

Para o historiador Bruno da Silva (2016) entrevistado, que trabalhou na FCJ até dezembro de 2016 como subcoordenador da Coordenadoria de Patrimônio Cultural, os laços com a germanidade já não alcançam os discursos patrimoniais como em décadas passadas, quando da época das imigrações. Ele entende que a agenda patrimonial na cidade, apesar de não mais ligada à história fundante de Joinville, ainda possui traços românticos, como que uma espécie de mentalidade romantizada do patrimônio, uma retórica, que geralmente vem do campo acadêmico. A crítica que o historiador faz é no sentido de que as pessoas da academia conhecem toda a parte da discussão teórica e conceitual do campo do patrimônio, por exemplo, o que é uma atribuição de valor a determinado bem cultural, no entanto, não conhecem minimamente como funciona o processo burocrático da preservação. Ele afirma que apenas quem pesquisa a legislação ou quem participou de uma Comissão é que terá uma experiência no campo. Por outro lado, quem está somente no campo acadêmico não tem ideia das demandas dos proprietários, das necessidades e da questão econômica. Sem a questão do mercado, não se mantém o bem. E essa parte parece que é descartada, pois não se quer mercantilizar a cultura. $\mathrm{O}$ entrevistado entende diferente, uma vez que acredita que o fator econômico tem que ser levado em consideração.

Levando em consideração as palavras do historiador entrevistado e a trajetória dos atores do campo do patrimônio na cidade de Joinville o que se percebe por ora é que as múltiplas identidades que se engendram na cidade são vistas também nos migrantes de outros estados 
brasileiros, como os paranaenses e de outras cidades vizinhas, que há poucas décadas migraram para a cidade que crescia industrialmente falando e acabaram se tornaram os novos atores a adentrarem na disputa pelo reconhecimento do que é patrimônio para Joinville.

Além desses migrantes, outro ator é, indiscutivelmente, a academia, representada no início dos processos de patrimonialização pela Univille - Universidade da Região de Joinville, através dos cursos de História e Mestrado em Patrimônio Cultural e Sociedade, mas depois também pela UniSociesc, por meio de seus cursos de graduação e pós-graduação em Engenharia e Arquitetura, que possui representatividade dentro da Comphaan desde os anos 2000.

É importante salientar também o mandato do prefeito Carlito Merss (PT), iniciado no ano de 2009, como um marco entre as fases das políticas públicas de preservação em Joinville. A sua gestão foi o momento de abertura para que outros grupos formadores da cidade fossem contemplados com direito à cultura e seu devido reconhecimento como patrimônio da cidade. Naim Andrade Tannus (2016), procurador do município afirmou em entrevista que o PT sempre foi um grupo político que buscou dar visibilidade aos grupos que "são minoritários, mas que estavam invisíveis, por exemplo, uma comunidade no bairro Floresta, comunidade de negros chamada Kenia Clube, foi reconhecida, recentemente, por meio do governo Merss. Houve outras aberturas, como a valorização das mulheres, dos homossexuais, com a Parada Gay de 2009, que foi muito marcante para a cidade" [depoimento verbal]. Nesse mesmo governo houve a promulgação da lei de inventário (Joinville, 2011), outra abertura legislativa no campo patrimonial.

Outros atores preponderantes no campo patrimonial foram os profissionais da museologia, arquivologia e arqueologia nos museus da cidade (Museu Nacional de Imigração e Colonização e Museu Arqueológico de Sambaqui), primordialmente nos anos 2000. Profissionais esses que não vieram de famílias de renome para a cidade e, muitas vezes, nem são nascidos em Joinville, são os de fora.

A noção da gente de fora pode ser entendida a partir das categorias dentro e fora ou familiar e exótico, trabalhadas por Gilberto Velho (1978) em seu texto Observando o familiar, em que o antropólogo, citando Roberto Da Matta, sugere problemas metodológicos quando vemos e encontramos o familiar em nossas pesquisas, mas não necessariamente o conhecemos e, às vezes, não vemos e encontramos o exótico, mas, até certo ponto, o conhecemos. Para Velho, nas sociedades complexas, dentro das familiaridades e exotismos, estão as hierarquias de poder. Em Joinville, os paranaenses, os novos professores da Univille e da Unisociesc e alguns profissionais que adentram ao campo do patrimônio, eram exóticos, porém, conhecidos, e, portanto, sofriam certa imposição de poder vinda dos descendentes de germânicos. 
Vários discursos e narrativas foram construídos nesses mais de cinquenta anos de agenda patrimonial. No entanto, para este estudo realizamos um recorte temporal entre os anos de 2013 a 2016 onde analisaremos como vem se reconfigurando o campo patrimonial da cidade de Joinville. Nessa análise, então, temos o intuito de averiguar como o campo do patrimônio na cidade vem/vinha se estruturando nessa última gestão (2013/2016) e para tanto, num segundo momento, trazemos alguns dados numéricos para fins de comparação das fases das políticas públicas de preservação do patrimônio joinvillense. Esses dados foram obtidos a partir da pesquisa de Tese de Doutoramento realizada junto ao Programa Interdisciplinar em Ciências Humanas, da UFSC, que defendi em fevereiro último (Autora1, 2017). A tese teve como tema principal as políticas públicas de preservação do patrimônio cultural da cidade de Joinville, tomando como um caso paradigmático a patrimonialização e a judicialização do Cine Palácio de Joinville. Por ora, o que se conclui é que o reconhecimento dos mais diversos discursos que engendram o que é patrimônio na cidade de Joinville é uma realidade a pouco tempo enfrentada. Essa mudança de paradigma vem sendo sentida há pouco mais de 10 anos. Esse debate vem abrindo brechas para outros olhares sobre o passado da cidade e também novos diálogos que nem sempre foram considerados em sua totalidade.

\section{Nova gestão, velhas questões}

Desde 2013, com uma nova gestão de membros na Comphaan que se estendeu até maio de 2016, quando houve nova mudança de gestão, observamos uma transfiguração de atitudes da Fundação Cultural. Explica-se: apesar de ainda haver muitos retrocessos, como por exemplos sistemas não digitais, dependência de acervo físico, houveram reconfigurações que se mostraram decisivas. Ao se vislumbrar processos intricados sob o ponto de vista burocráticojurídico, especialmente por haver um aumento de ações judiciais ajuizadas na comarca de Joinville, bem como novos questionamentos sobre a aplicabilidade das Leis de Tombamento e Inventário, algumas dessas atitudes vieram no caminho de amparar tecnicamente sobre quais eram os limites da agenda da Fundação Cultural e da Comphaan.

Como forma de averiguar esses limites, a diretoria da FCJ enviou ofício de $n^{\circ}$ 428/2013 para a Procuradora Geral Municipal de Joinville, solicitando orientações quanto às medidas judiciais e extrajudiciais cabíveis para assegurar proteção aos imóveis que compõem o patrimônio cultural da cidade. A motivação desse ofício foi exatamente estabelecer claramente para os funcionários da FCJ os limites de sua atuação. Essas orientações alcançavam os bens tombados e os bens em processo de tombamento, assim como a possibilidade de aplicação de 
Termo de Ajustamento de Conduta (TAC) para os proprietários desses bens, caso algum deles agisse por ação ou omissão causando algum dano a bem protegido.

O procurador do município Naim A. Tannus respondeu ao ofício com a concordância do Procurador-Geral Eduardo Buzzi, em 06 de setembro de 2013. No documento de resposta da PGM, o Procurador mencionou todas as leis municipais que embasam a proteção do patrimônio, assim como citou a Constituição Federal como Lei Maior e as modalidades de diferentes níveis de proteção: inventário, tombamento, desapropriação e outras formas de acautelamento e preservação. No decorrer do documento, a PGM afirmou que, com a publicação da norma 363 de novembro de 2011, Lei Complementar que instituiu o IPCJ Inventário do Patrimônio Cultural de Joinville, todos os bens que deveriam de alguma forma serem protegidos deveriam ser tombados ou inventariados, não havendo qualquer garantia legal para proteger os bens que não estivessem dispostos no Livro Tombo da cidade.

Na sequência do documento, a PGM denominou como limitação administrativa a condição de um bem inventariado ou tombado perante o Estado, por haver intervenção na propriedade particular por parte do poder público, especialmente caso os proprietários comprovem a situação de miserabilidade, a fim de manter o imóvel protegido. O Procurador afirmou que daí "resulta ao poder público a obrigação subsidiária da preservação em caso de impossibilidade do particular de realizá-la" [depoimento verbal]. E sugeriu o empenho da Fundação Cultural em auxiliar os proprietários a buscarem benefícios fiscais junto ao SIMDEC - Sistema Municipal de Desenvolvimento pela Cultura, por meio do Fundo Municipal de Apoio à Cultura e do Mecenato. Citou ainda a outorga onerosa do direito de construir, que, "sem dúvida, em um futuro próximo poderá trazer bons resultados para auxiliar na preservação do patrimônio histórico local" [depoimento verbal], já que até o momento não foi regulamentado.

Quanto à possibilidade de se ajuizarem Ações Cíveis Públicas, a PGM se manifestou favoravelmente. Sugeriu ainda que, antecipadamente, conforme fosse o caso, a FCJ ajuizasse ações cautelares a fim de evitar a concretização de danos potenciais aos bens e aos direitos de valor cultural. "Tanto o município (administração direta) como essa Fundação (administração indireta) possuem legitimidade para propor a Ação Principal e a Ação Cautelar [...]" [depoimento verbal], frisou o Procurador. Ele ainda complementou que poderá propor, por meio da Procuradoria, as respectivas ações em nome da Fundação Cultural. Para isso, são necessárias algumas providências antes de intentar as ações, quais sejam:

1 - Avaliar as condições econômico-financeiras do proprietário/possuidor da coisa; 
RELACult - Revista Latino-Americana de Estudos em Cultura e Sociedade

Revista Latinoamericana de Estudios en Cultura y Sociedad | Latin American Journal of Studies in Culture and Society V. 03, no 02, mai-ago., 2017, p. 172-189| relacult.claec.org e-ISSN 2016/Atual: 2525-7870 | e-ISSN 2015/2016: 2447-018X

2 - Verificar a possibilidade de celebração de Termo de Ajustamento de Conduta (TAC) com proprietário/possuidor da coisa, prevendo a realização de ações concretas e com prazo estabelecido, inclusive com previsão de multa por descumprimento;

3 - Caso haja recusa da celebração do TAC, remeter a PGM o respectivo processo administrativo contendo as informações necessárias para a interposição da Ação Civil Pública (ACP) ou Ação Cautelar.

O Procurador ainda ressaltou que mesmo celebrado o TAC com o infrator, nada impede que seja feita a representação à autoridade policial competente ou ao Ministério Público, caso a conduta seja tipificada como crime. Ele arrematou, por fim, que o legitimado para assinar o TAC, se aceito pelas partes, seria o presidente da FCJ ou pessoa habilitada por procuração para tanto, depois de ouvida a Comphaan.

Numa reunião da Comphaan de 2016, assim mais de três anos após o recebimento da resposta ao ofício da FCJ, houve a aprovação do modelo padrão de TAC, bem como do modelo padrão de cálculo dos danos mitigados (Gráfico 1) [Ata Comphaan, 20 jul. 2016]. Ambos os documentos dão subsídios para evitar processos judiciais, mas também são usados quando acordos extrajudiciais são descumpridos pelos proprietários de bens protegidos, amparando futuras execuções judiciais junto ao Poder Judiciário.

Participei (Autora 1) das reuniões de um grupo especial designado mormente para resolver esses dois documentos por mais de seis meses, e apesar da demora em se organizar tais modelos, creio que um importante passo foi dado a partir dessa documentação. Afinal, a Fundação Cultural, por meio da Coordenadoria de Patrimônio, tomou para si a responsabilidade total em negociar os Termos de Ajustamento de Conduta, conforme bem arguiu o Procurador do Município. E desde o envio desse ofício à PGM e sua respectiva resposta, em 2013, até a aprovação dos documentos (Modelo de Cálculo e Modelo de Termo), em agosto de 2016, já se somam mais de dez processos com possibilidade de assinatura de acordo.

Gráfico 1 - Cálculo para valoração econômica dos danos a bens culturais materiais 
RELACult - Revista Latino-Americana de Estudos em Cultura e Sociedade

Revista Latinoamericana de Estudios en Cultura y Sociedad | Latin American Journal of Studies in Culture and Society

V. 03, n 02 , mai-ago., 2017, p. 172-189| relacult.claec.org e-ISSN 2016/Atual: 2525-7870 | e-ISSN 2015/2016: 2447-018X

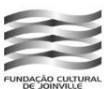

\begin{tabular}{|c|c|c|c|c|c|}
\hline \multicolumn{6}{|c|}{ CÁLCULO PARA VALORAÇÃO ECONÔMICA DOS DANOS A BENS CULTURAIS MATERIAIS } \\
\hline \multicolumn{4}{|c|}{ PLANILHA DE CÁLCULO NÚMERO: } & \multicolumn{2}{|c|}{ SITUAÇÃO: } \\
\hline \multicolumn{4}{|c|}{ ENDEREÇO: Rua do Principe } & \multicolumn{2}{|l|}{ PROTEÇÃO LEGAL DE PRESERVAÇÃ̃: } \\
\hline \multicolumn{4}{|c|}{ INSCRIÇÃO IMOBILIÁRIA: } & \multicolumn{2}{|l|}{ PROCESSO DE TOMBAMENTO: } \\
\hline \multicolumn{4}{|c|}{ PROPRIETÁRIO: } & \multicolumn{2}{|l|}{ LIVRO TOMBO: } \\
\hline \multicolumn{4}{|c|}{ LOCATÁRIO: } & \multicolumn{2}{|l|}{ INSTRUÇÃO DE INVENTARIAÇÃO: } \\
\hline \multicolumn{4}{|l|}{ DATA: } & \multicolumn{2}{|l|}{ IPCJ -LIVRO DE REGISTRO BENS IMÓVEIS: } \\
\hline \multicolumn{6}{|c|}{ CÁLCULO DO DANO METODOLOGIA COMPHAAN (Joinville/SC) } \\
\hline \multicolumn{6}{|c|}{ QUADRO DE AFERIÇÃO DOS DANOS } \\
\hline & Aspectos & Pontos & Pontuação & Conceito Gerais & Observação \\
\hline 1. & \multicolumn{5}{|c|}{$\begin{array}{l}\text { LC } 363 \text { Art. 45. A graduação do valor das multas previstas no artigo anterior será determina da pela autoridade fiscal } \\
\text { municipal, ouvida a Comissão de Patrimônio Histórico, Arqueológico, Artístico e Natural do Município de Joinville, }\end{array}$} \\
\hline 1.1 & \multicolumn{5}{|c|}{ I - O nível de preservação, conforme prevê o art. 8 da presente Lei; } \\
\hline 1.1 .1 & Preservação Integral - PI & 0,10 & & & \\
\hline 1.1 .2 & \multirow{2}{*}{\multicolumn{5}{|c|}{\begin{tabular}{l|c} 
Pres ervação Parcial - PP & 0,05 \\
|l - A gravidade do dano causado ao bem;
\end{tabular}}} \\
\hline \multirow{2}{*}{$\frac{1.2}{1.2 .1}$} & & & & & \\
\hline & Severo & 0,20 & & & \\
\hline 1.2 .2 & Médio & 0,10 & & & \\
\hline 1.2 .3 & Pequeno & 0,05 & & & \\
\hline \begin{tabular}{|l|l|l}
1.3 & III - O valor do bem protegido; \\
\end{tabular} & \multicolumn{5}{|l|}{ III - O valor do bem protegido; } \\
\hline 1.3 .1 & Tombamento Nacional & 0,20 & & & \\
\hline 1.3 .2 & Tombamento Estadual & 0,15 & & & \\
\hline 1.3 .3 & $\begin{array}{l}\text { Tombamento Municipal e } \\
\text { Registrado no IPCJ }\end{array}$ & 0,12 & & & \\
\hline \multirow{3}{*}{\multicolumn{6}{|c|}{ 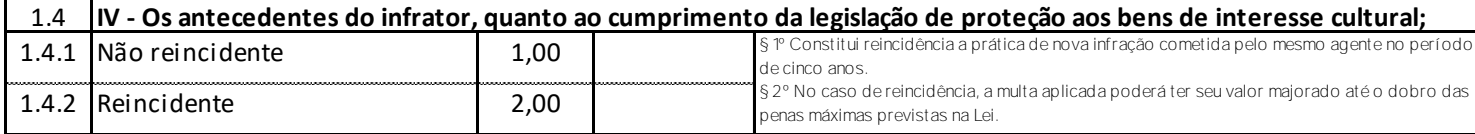 }} \\
\hline & & & & & \\
\hline & & & & & \\
\hline \multicolumn{6}{|c|}{ V - A situação econômica do infrator. } \\
\hline 1.5 .1 & Alta & 0,00 & & & \\
\hline 1.5.2 & Média & 0,07 & & & \\
\hline 1.5 .3 & Baixa & 0,15 & & & \\
\hline & TOTAL DA AFERIÇÃO (P) & & 0,00 & & \\
\hline 3 & Valor de indenização & I & & & \\
\hline 3.3 & Pontos do quadro de aferição & $\mathbf{P}$ & 0,00 & & \\
\hline 3.4 & Valor Inicial somente material & V & & $V=V U . A T E$ & $\mathrm{R} \$$ \\
\hline 3.4 .1 & Valor Unitário de dano & $\mathrm{VU}=$ & $1,5 \times C \cup B=$ & $2.420,15$ & \\
\hline 3.4 .2 & Área afetada pelo dano & ATE $=$ & $\mathrm{m} 2=$ & & \\
\hline 3.5 & Total do Valor de indenizaça & & & $I=V \times P$ & $\mathbf{R} \hat{\mathbf{s}}$ \\
\hline & arlavel $=$ CUB Junho/ZO16 - Custo & & sico da & $1.613,43$ & \\
\hline & & & CULO FINA & L DO DANO & \\
\hline 4. & Valor final em Unidade Padrão & lunicipal - & $\mathrm{JPM}=$ & & - \\
\hline 4.1 & Variável = Valor da UPM/Abril & & & & 263,53 \\
\hline 4.2 & $\begin{array}{l}\text { LC } 363 \text { Art. 44. A ampliação, mutilaç: } \\
\text { demolição do bem inventariado no II } \\
\text { Arqueológico e Natural do Município } \\
\text { autorizada, executada em desacord } \\
\text { (dez mil) Unidade Padrão Municipal. }\end{array}$ & $\begin{array}{l}\text {, transport } \\
\text { CM, sem apr } \\
\text { le Joinville e } \\
\text { sujeitará o } \\
\text { JPM. }\end{array}$ & $\begin{array}{l}\text {, aplicação de c } \\
\text { ovação da Comi } \\
\text { autorização da } \\
\text { infrator à aplica }\end{array}$ & $\begin{array}{l}\text { comunicação visual, destruição parcial ou } \\
\text { issão de Patrimônio Histórico, Artístico, } \\
\text { Fundação Cultural de Joinville, ou se } \\
\text { ação de multa no valor de } 10 \text { (dez) a } 10.000\end{array}$ & \\
\hline 4.3 & Valor minimo de 10 UPM & & & & $2.635,30$ \\
\hline 4.4 & Valor máxino de 10.000 UPM & & & & $2.635 .300,00$ \\
\hline 5. & Valor do Dano ao Patrimônio & $\begin{array}{r}\text { ultural ( } v \\
\text { Mur }\end{array}$ & $\begin{array}{l}\text { lor de } 10 \text { (de } \\
\text { icipal - UPM. }\end{array}$ & z) a 10.000 (dez mil) Unidade Padrão & $\mathbf{R} \$$ \\
\hline
\end{tabular}

Fonte: Ata Comphaan, 20 jul. 2016, Arquivo da Fundação Cultural de Joinville, 2016.

As principais ponderações sobre o Modelo de Cálculo, do quadro acima, que se podem destacar são referentes aos aspectos de aferição do dano. A Lei do IPCJ (Joinville, 2011) 

e-ISSN 2016/Atual: 2525-7870 | e-ISSN 2015/2016: 2447-018X

determina, em seu art. 45, que a valoração da multa deverá levar em consideração o nível de preservação do bem, que no cálculo foi estabelecido em preservação integral ou parcial; a gravidade do dano, valorado em severo, médio e pequeno; e o valor do bem protegido, que estipulou diferença entre tombamento nacional, estadual e municipal ou registrado no IPCJ. Ainda deve ser levado em consideração se o infrator é reincidente, o que majora o valor da multa em 50\%, e a situação econômica do infrator, sendo valorado inversamente de alta, média a baixa. Ao fim do cálculo, o valor do dano ao patrimônio não poderá ser menor que 10 Unidades Padrão Municipal (UPM) nem maior que 10.000 UPM - em abril de 2016, uma unidade representava o importe de $\mathrm{R}$ \$263,53 (valor de referência apresentado no Gráfico). Em março de 2017 o valor era de R \$ 270,21, portanto, havendo uma pequena variação.

A atuação da Procuradoria tem sido intensa em parceria com a FCJ, especialmente após a publicação da Lei do IPCJ, em 2011, mas essa unidade jurídica não exerce seus serviços apenas em favor da Fundação Cultural. Por isso, em entrevista, Naim A. Tannus (2016) explicou como é o trabalho da Procuradoria. Ele disse que

\begin{abstract}
Não temos área especializada, fazemos de tudo, área ambiental, urbanística, tributário, tudo... Lógico tem um ou outro [Procurador] que fica mais concentrado, mas não tem uma departamentalização. Eu mesmo faço parecer de tudo que é coisa, fico muito no legislativo também, projetos de lei, analiso os projetos, os decretos, os contratos. Temos muita variedade de assunto, tem muitas permissões de serviço, serviço público, tem que passar tudo por aqui, orientações, e tem muita demanda, e na área de patrimônio também, consultas, muitos recursos [depoimento verbal].
\end{abstract}

Frente à grande gama de áreas de atuação da PGM, percebe-se que nem sempre os Procuradores davam conta da demanda advinda da Fundação, que até o momento não possui um Procurador exclusivo ou algum técnico da área jurídica para orientá-la nas questões processuais.

Embora haja sinais de estabilidade das políticas públicas e indícios de ressonância das ações da Comphaan junto à população da cidade, em contraponto ainda a pedidos de demolição, nessa fase do campo do patrimônio de Joinville (2013-2016) foi possível realizar alguns diagnósticos.

\title{
2.6. A preservação institucionalizada em números
}

O ‘segundo’ Livro do Tombo da cidade contava até o fim da gestão 2013-2016 com 116 tombamentos, 57 bens em processo de tombamento, dois bens protegidos apenas pelo 

e-ISSN 2016/Atual: 2525-7870 | e-ISSN 2015/2016: 2447-018X

inventário e 12 bens em processo de inventariação ${ }^{3}$. No entanto, é importante frisar que, diferentemente do sistema nacional, gerido pelo IPHAN, a FCJ não detém quatro Livros do Tombo, subdivididos por temas. Trata-se de apenas um livro aberto em sua segunda edição ${ }^{4}$, feita nos anos 2000, década que realmente se iniciou os primeiros tombamentos municipais.

A Fundação Cultural de Joinville incluiu no Livro do Tombo do patrimônio da cidade todos os tombamentos em nível estadual e federal, para que tais bens também recebessem a proteção da esfera municipal. Afinal, o município possui competência subsidiária à competência federal e estadual. Portanto, com essas inclusões ao livro municipal, a análise que se fará a seguir conta com os tombamentos originados na municipalidade e também os oriundos do IPHAN e da FCC - Fundação Catarinense de Cultura, que foram incluídos posteriormente ao Livro do Tombo de Joinville.

De meados dos anos de 1930, quando ocorre o primeiro tombamento federal na cidade de Joinville, o tombamento do Museu de Imigração, em 1939, por meio do SPHAN; até o ano de 2002, considera-se uma fase em que apenas havia tombamentos federais e estaduais, e portanto, é anterior ao primeiro tombamento compulsório municipal, ocorrido em 2003, quando tombou o conjunto arquitetônico do Cine Palácio de Joinville, objeto de análise da Autora 1 (2017). Já do periodo de 2003 a 2011 considera-se o periodo ou fase de tombamentos, quando ocorre o maior número de tombamentos na cidade e a partir de 2011 é considerada a fase dos inventários, especialmente após a promulgação da lei do IPCJ, que se estende até os dias atuais. No entanto, este recorte analítico se fixou entre os anos de 2013 a 2016, assim os dados serão até meados do ano de 2016.

No Gráfico 2, abaixo, observam-se os números de tombamentos em seus diferentes níveis: federal, estadual e municipal, levando em consideração a datação das fases, conforme explicitado acima.

\footnotetext{
${ }^{3}$ CPC. Relação de bens tombados no município de Joinville (Tombamento Municipal, Estadual e Federal). Coordenação de Patrimônio Cultural: Fundação Cultural de Joinville, Joinville, 2016. Atualizado em julho, 2016.

${ }^{4}$ Houve um primeiro Livro Tombo aberto nos anos oitenta que foi perdido. Nesse Livro foi tombado a Alameda Brustlein, conhecida ordinariamente por Rua das Palmeiras.
} 
Gráfico 2 - Níveis de tombamento na cidade de Joinville, 2016.

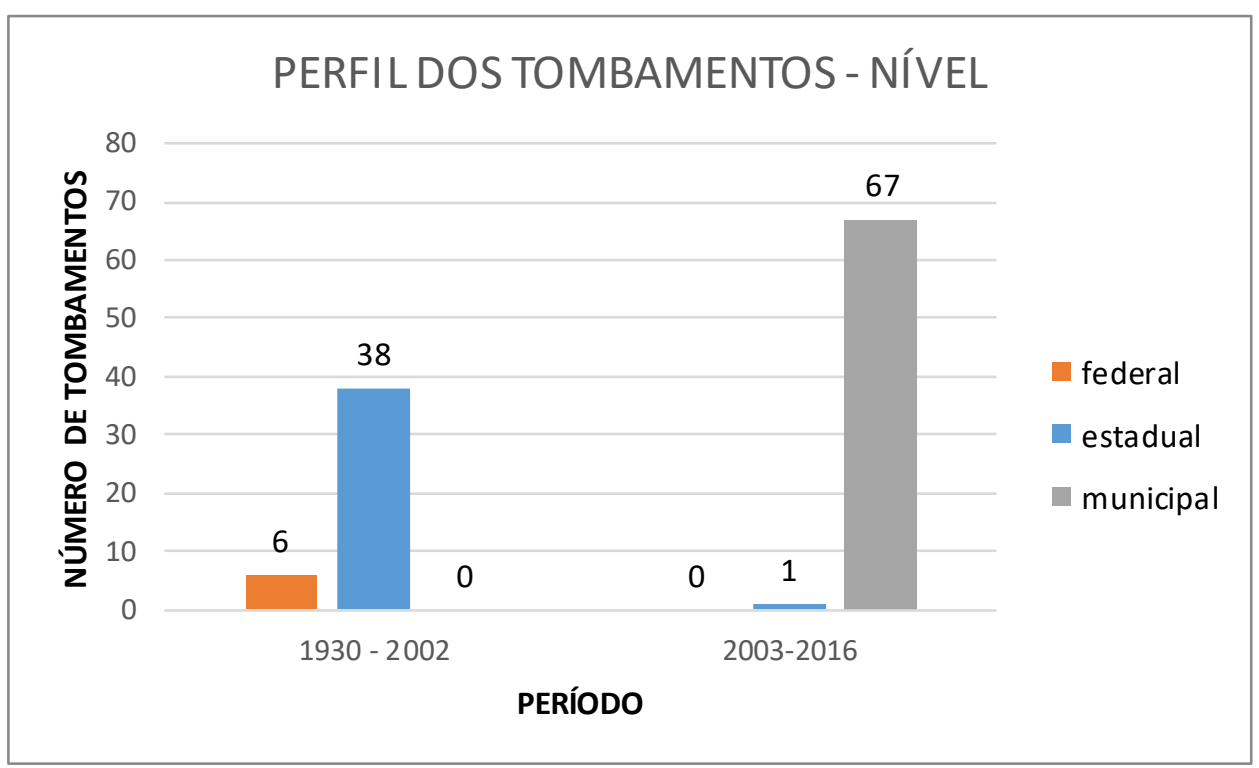

Fonte: Criação de Christiane Heloisa Kalb, dados da relação de bens tombados no município de Joinville (Tombamento Municipal, Estadual e Federal). Coordenação de Patrimônio Cultural: Fundação Cultural de Joinville, Joinville, 2016.

O Gráfico 2 apresenta uma relação preponderante de bens tombados nas esferas federal e estadual na primeira fase de políticas públicas em Joinville. A partir do tombamento do conjunto arquitetônico Cine Palácio, o primeiro municipal, em 2003, esse perfil de tombamento por meio de decreto municipal é que impera até os dias mais atuais.

De acordo com o Livro do Tombo de Joinville, há a seguinte cronologia de número de tombamentos por ano, a partir dos atos municipais de preservação de patrimônio na cidade:

Gráfico 3 - Cronologia por ano - Número de Tombamentos

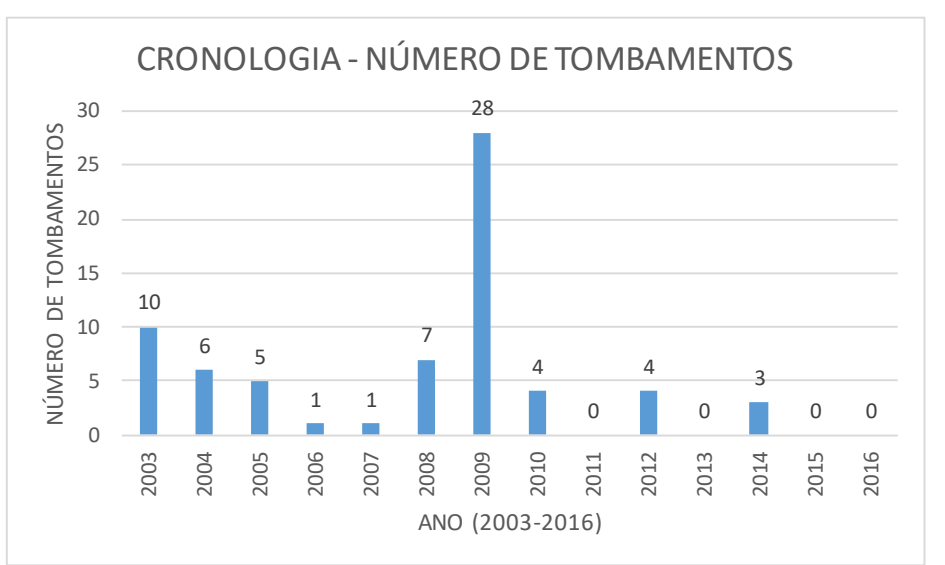


RELACult - Revista Latino-Americana de Estudos em Cultura e Sociedade

Revista Latinoamericana de Estudios en Cultura y Sociedad | Latin American Journal of Studies in Culture and Society V. 03, nº 02, mai-ago., 2017, p. 172-189| relacult.claec.org e-ISSN 2016/Atual: 2525-7870 | e-ISSN 2015/2016: 2447-018X

Fonte: Criação de Christiane Heloisa Kalb, dados da relação de bens tombados no município de Joinville (Tombamento Municipal, Estadual e Federal). Coordenação de Patrimônio Cultural: Fundação Cultural de Joinville, Joinville, março 2016.

E o seguinte número de tombamentos, em razão das fases de políticas públicas de preservação de patrimônio de Joinville, é mostrado conforme o Gráfico 4. Frisando que na primeira coluna, datada de 1930 a 2002, consideram-se as fases anteriores ao primeiro tombamento compulsório municipal, quando apenas havia tombamentos federais e estaduais. Já do periodo de 2003 a 2011 considera-se o periodo de tombamento e a partir de 2011, a fase dos inventários.

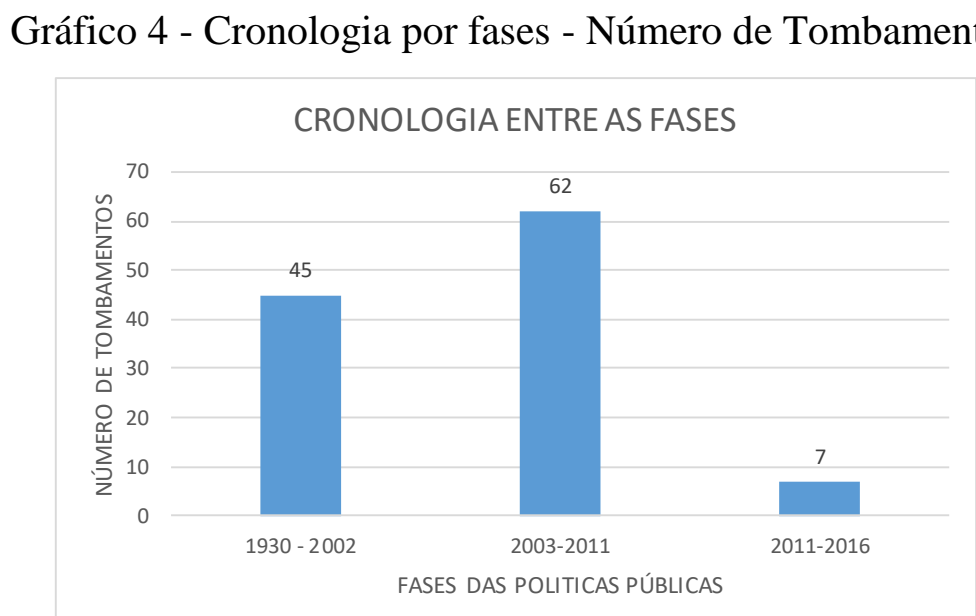

Fonte: Criação de Christiane Heloisa Kalb, dados da relação de bens tombados no município de Joinville (Tombamento Municipal, Estadual e Federal). Coordenação de Patrimônio Cultural: Fundação Cultural de Joinville, Joinville, março 2016.

O Gráfico 3, portanto, sugere a identificação das fases das políticas públicas municipais de preservação em razão do número de tombamentos ocorridos desde o primeiro, em 2003, até março de 2016. Percebe-se que há uma certa descontinuidade, um desequilíbrio na quantidade de tombamentos por ano, especialmente se considerarmos o ano de 2009, em que houve quase 30 tombamentos. No entanto, de acordo com os dados do Gráfico 4, ao mesmo tempo se pode auferir que entre 2003 e 2010 houve uma consolidação das ações de preservação, com 62 tombamentos municipais - o que vai ao encontro da fase dos tombamentos, se compararmos com as outras fases, nas quais se homologaram apenas sete tombamentos, e nenhum antes de 2003.

Quanto ao perfil dos bens tombados na cidade, em razão do domínio, tem-se as seguintes estruturas, de acordo com o Gráfico 5, abaixo: 
Gráfico 5- Perfil dos tombamentos quanto à propriedade

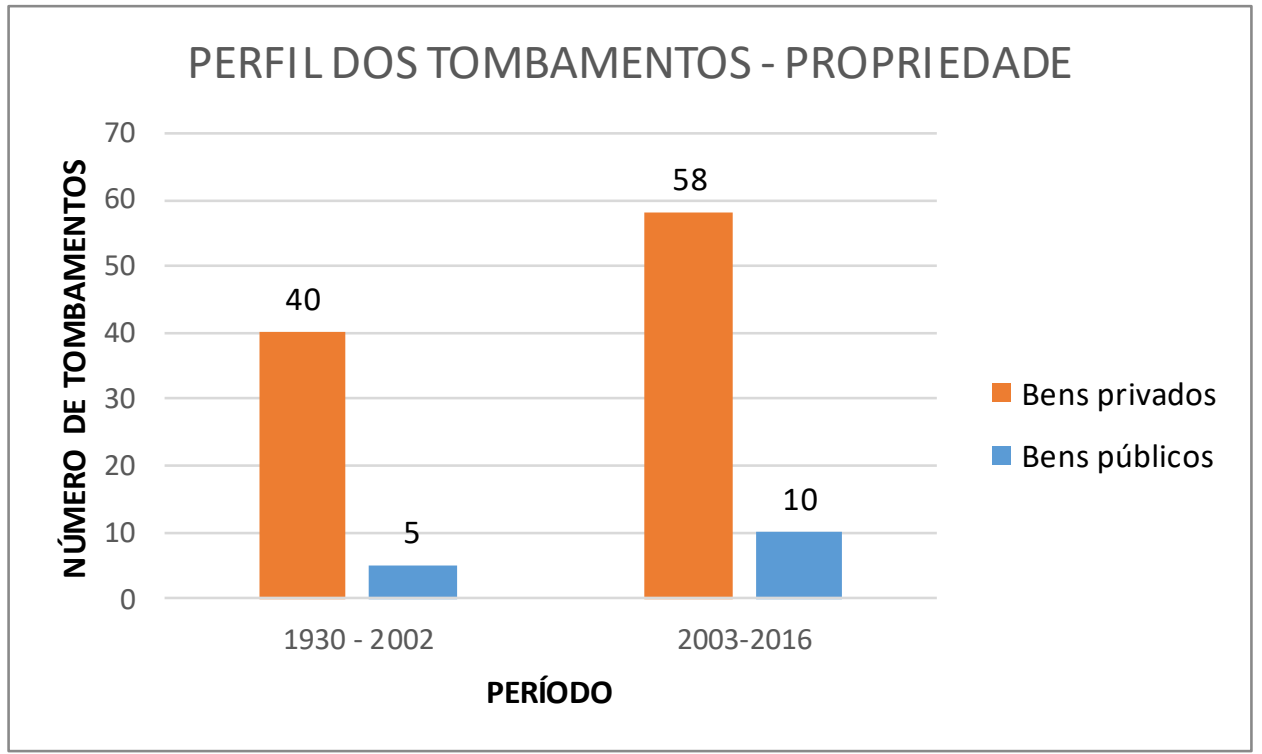

Fonte: Criação de Christiane Heloisa Kalb, dados da relação de bens tombados no município de Joinville (Tombamento Municipal, Estadual e Federal). Coordenação de Patrimônio Cultural: Fundação Cultural de Joinville, Joinville, março 2016.

Tanto no período que antecede o primeiro tombamento realizado pelo município compulsoriamente quanto após 2003, a predominância de tombamentos é em bens de domínio privado, havendo menos de $20 \%$ sobre o total de tombamentos por período de bens públicos. Assim, apesar das dúvidas que surgiram durante diversas reuniões da Comphaan quanto à possibilidade jurídica de se tombarem bens privados antes da fase dos tombamentos, o que se vê no Gráfico 5 é uma segurança estabelecida perante tal situação. Prova disso é que a maior parte dos tombamentos, antes e depois do início dos atos municipais, foi de bens de caráter privado.

No Gráfico 6, abaixo, identificamos a localização desses bens, subdividindo-os em área urbana e área rural. 
Gráfico 6 - Perfil dos tombamentos quanto à localização

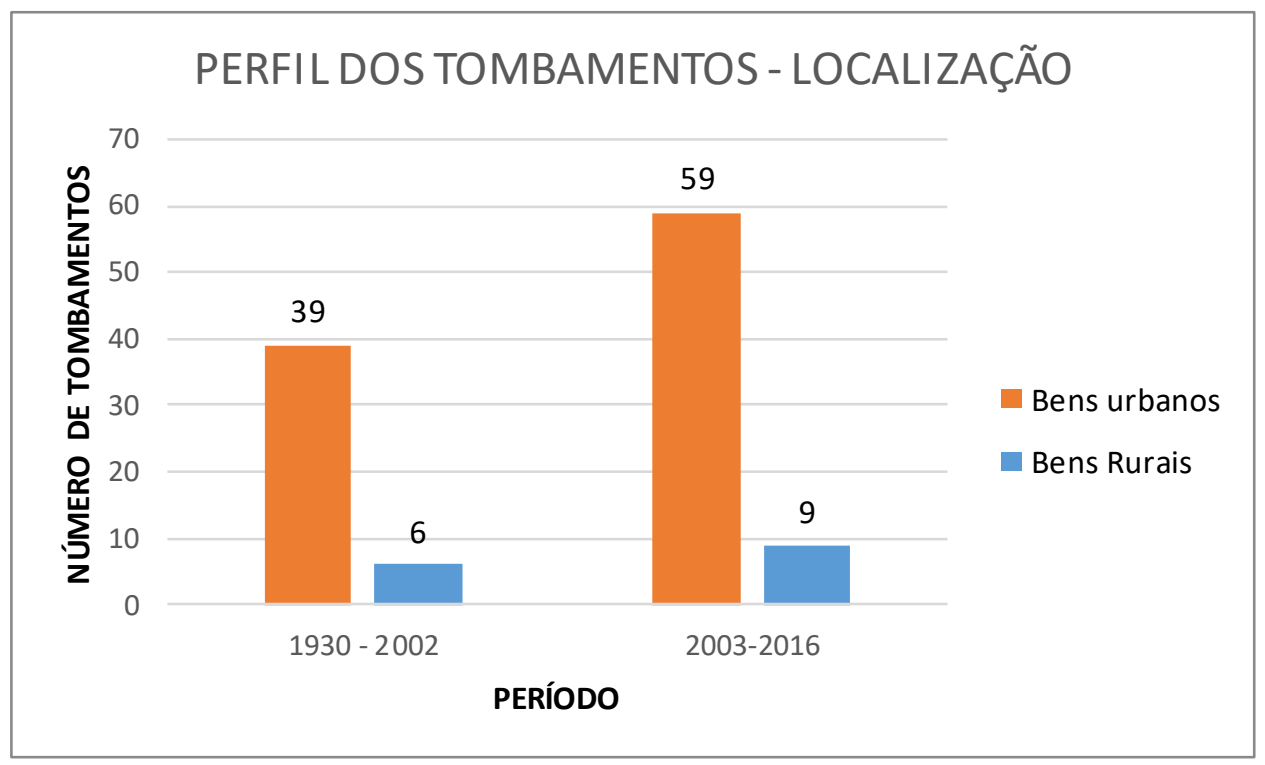

Fonte: Criação de Christiane Heloisa Kalb, dados da relação de bens tombados no município de Joinville (Tombamento Municipal, Estadual e Federal). Coordenação de Patrimônio Cultural: Fundação Cultural de Joinville, Joinville, março 2016.

Além do perfil quanto à propriedade dos bens tombados, ainda averiguei a localização deles. Em maioria absoluta, os bens protegidos tanto por tombamento municipal quanto estadual e federal estão em área urbana. No período que se estende da década de 1930 até 2003, houve apenas seis tombamentos rurais, ao lado de 39 urbanos. Esses tombamentos foram realizados originariamente pelo IPHAN ou pela FCC. Já na fase dos tombamentos e na fase dos inventários houve nove tombamentos em área rural e 59 de bens urbanos.

Apesar de Joinville contar com uma considerável área rural, especialmente na região de Pirabeiraba, Quiriri e Estrada Dona Francisca, os bens que poderiam gerar interesse de preservação podem ter se perdido pelo uso de estruturas em madeira ou pela falta de interesse dos gestores do campo do patrimônio em abranger essas áreas da cidade, embora tivesse havido alguns projetos que contemplassem essas áreas, como o Roteiros Nacionais de Imigração e o Projeto Memória de Joinville. Houve também um novo Projeto de Inventário abrangendo a parte central de Pirabeiraba que está sendo finalizado [Ata Comphaan, 14 dez. 2016].

No Gráfico 7, mostramos o perfil dos bens tombados quanto à sua função, ou seja, sua atividade fim, ainda que contemporaneamente tenham sido abandonados ou alterados em sua funcionalidade. 
Gráfico 7 - Perfil dos tombamentos quanto à função

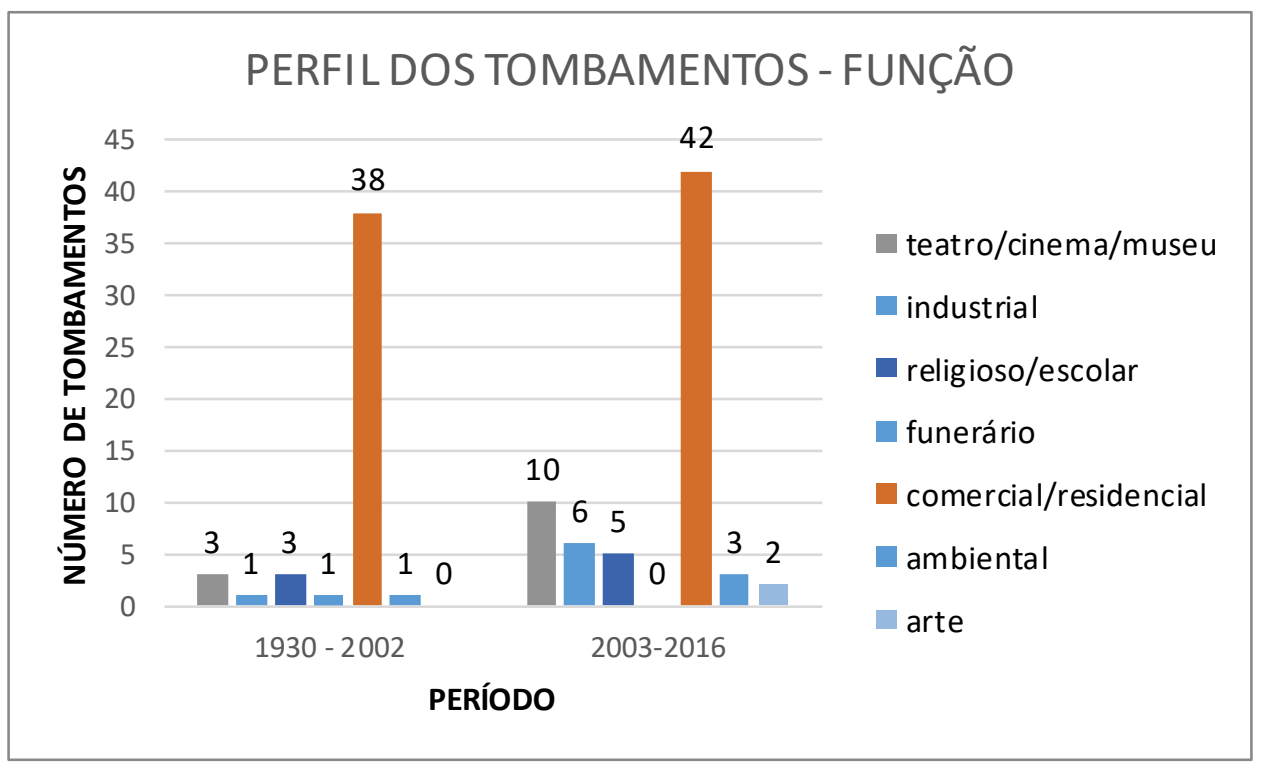

Fonte: Criação de Christiane Heloisa Kalb, dados da relação de bens tombados no município de Joinville (Tombamento Municipal, Estadual e Federal). Coordenação de Patrimônio Cultural: Fundação Cultural de Joinville, Joinville, março 2016.

O Gráfico 7 retrata que, em sua maioria, os tombamentos são de residências ou antigos comércios, havendo uma pequena variação em tombamentos de teatros, cinemas e museus; de bens industriais, como chaminés, pontes e fábricas; de bens de caráter ambiental, como parques e áreas verdes; e o último perfil, de dois bens de origem artística - um painel do artista Fritz Alt e um guardanapo comemorativo encontrado no Harmonia Lyra, também tombado. Tal fato se repetiu anos antes, quando apenas havia tombamentos federais e estaduais. Grande parte dos tombamentos foi de residências e casas de comércio, em especial, localizadas na Rua do Príncipe, no Centro da cidade. Ao lado desses tombamentos houve ainda a proteção a dois teatros, um bem de origem industrial, um funerário, que seria o Cemitério dos Imigrantes, e um ambiental, o Parque Schmalz, de propriedade particular, ambos protegidos pelo IPHAN.

\section{Conclusões}

Com o diagnóstico estatístico sobre o perfil dos bens tombados na cidade de Joinville, pudemos observar uma relação entre as fases das políticas públicas de preservação do patrimônio da cidade e a construção do discurso do campo patrimonial que se fez de Joinville. A contribuição de Chartier (1990) sobre isso é salutar, pois ele entende que há manipulação nas representações sociais: 
As representações do mundo social assim construídas, embora aspirem à universalidade de um diagnóstico fundado na razão, são sempre determinadas pelos interesses de grupo que as forjam. Daí, para cada caso, o necessário relacionamento dos discursos proferidos com a posição de quem os utiliza [...]. As percepções do social não são, de forma alguma, discursos neutros: produzem estratégias e práticas (sociais, escolares, políticas) que tendem a impor uma autoridade à custa de outros, por elas menosprezadas, a legitimar um projeto reformador ou a justificar, para os próprios indivíduos, as suas escolhas e condutas. Por isso esta investigação sobre as representações supõe-nas como estando sempre colocadas num campo de concorrências e de competições cujos desafios se enunciam em termos de poder e de dominação (1990, p. 17).

A preservação dos antigos centros ou de partes específicas das cidades, como bairros históricos, no Brasil ou no exterior, exige a revisão de conceitos fundamentais, como: a preservação do patrimônio, o novo uso conferido às áreas preservadas e, especialmente, as diferentes interpretações do passado histórico urbano. Isso ocorre seja pelo fato de essas áreas terem admitido diferentes utilizações em função do crescimento das cidades, seja pelos usos que edifícios tombados assumem dentro da trama urbana atualmente. É difícil tratar a questão em toda sua complexidade se a opção for um olhar nostálgico que valorize apenas a preservação por si só, por meio das escolhas que tombam os bens e de determinados grupos específicos, sem averiguar propriamente se os sistemas de proteção encontram ressonância junto à população.

Uma grande carência observada durante as reuniões da Comphaan (Atas Comphaan, 2013-2016) é a falta de agilidade na tomada de decisão sobre obras de restauração ou reciclagem em bens protegidos. O que ocorre, normalmente, é que os proprietários ou os inquilinos responsáveis pela obra precisam requerer tais alterações à Comphaan, o que nem sempre é respondido num prazo viável e diretamente na primeira reunião da Comissão, quando da entrada do pedido. $\mathrm{O}$ interessado precisa passar por todo um sistema burocrático e lento. Primeiro, ingressa com uma Consulta Prévia, que se chama Consulta Amarela, junto à SEINFRA, que, caso se trate de um imóvel protegido por tombamento ou qualquer outro sistema, encaminha tal consulta à FCJ. Caso haja necessidade de deliberação colegiada, a Fundação Cultural encaminha para a Comphaan decidir sobre a solicitação. Muitas vezes, há a necessidade do deslocamento de um técnico (ou mais de um) da Coordenadoria de Patrimônio Cultural, para analisar in locu a situação do imóvel, o que pode gerar mais demora e, consequentemente, descontentamento dos usuários do imóvel.

Apesar da existência das regulamentações dos sistemas de proteção (particularmente tombamento e inventário, Joinville, 1980 e 2011), não há regras bem esclarecidas para os proprietários desses bens atingidos pelo tombamento ou inventariação no que concerne às possibilidades de incentivos fiscais e proibições relativas àquele patrimônio. Os proprietários simplesmente recebem a notificação e, quando se sentem lesados, buscam de todas as formas 
os recursos jurídicos possíveis para impugnar o processo administrativo de tombamento ou inventário, por isso, o interesse da FCJ em se munir do aporte teórico jurídico para suas ações frente os proprietários de bens protegidos ou em processo.

Haveria a necessidade de um empoderamento emancipatório, em que as decisões tomadas pela Comphaan, que tem o poder de autoridade local, fossem em consonância com o que a população local quer para seu patrimônio, para sua cidade. Ou ainda, que se implantasse a possibilidade de um recurso pessoal, onde o proprietário pudesse se manifestar verbalmente, durante as reuniões da Comphaan. Numa espécie de gestão compartilhada envolvendo estratégias de convencimento.

A falta de diálogo ainda é um problema que coloca muitas vezes a Comissão de Patrimônio num papel de vilã, e isso se repete em outros órgãos de proteção patrimonial também em níveis estaduais e federais, pois ao invés de haver uma educação para o patrimônio, em que as pessoas conheçam e se reconheçam perante àquele bem cultural o que acontece na maioria das vezes é a decisão pelo tombamento ou inventário de 'cima para baixo', sem nem ao menos ouvir o que as pessoas têm a dizer. Ao longo desta pesquisa, reconheceu-se o discurso autorizado do campo do patrimônio em diferentes tempos e espaços dentro de Joinville, confirmando a hipótese de que se trata de um discurso atolado de rachaduras e rugosidades, marcado por embates, disputas, contradições, visões e interesses, tudo sobre patrimônio, cidade e passado. O debate se estende e abre brechas para outros olhares, mas hoje ainda a discussão é toda feita por meio de papéis, pura burocracia jurídica, zero diálogo.

\section{Referências}

Autora1. Do instante esplêndido à decadência: Patrimonialização e judicialização do Cine Palácio de Joinville / Autora; orientadora, Maria Bernardete Ramos Flores; coorientadora, Alicia Norma Gonzalez Castells. - Florianópolis, SC, 2017.

CHARTIER, R. A. História Cultural: entre práticas e representações. Lisboa: DIFEL, 1990, $248 \mathrm{p}$.

COELHO, I. Pelas tramas de uma cidade migrante. Joinville: Editora da Univille, 2011.

CORREA, M. C. L. Identificação, levantamento e contextualização histórica do patrimônio edificado do município de Joinville. Jaraguá do Sul: Projeto de Iniciação Científica. Curso de Arquitetura e Urbanismo, 2013.

ELIAS, Norbert. Os alemães: a luta pelo poder e a evolução do habitus nos séculos XIX e XX. Trad. Alvaro Cabral. Rio de Janeiro: Jorge Zahar, 1997.

FCJ. Atas das reuniões da COMPHAAN. Reuniões da Comissão de Patrimônio. Joinville: Fundação de Cultura de Joinville. 2013- 2016. 
FCJ. Ofícios entre FCJ e PGM - Procuradora Geral do Município. Joinville: Fundação de Cultura de Joinville, 2013.

FCJ, CPC. Relação de bens tombados no município de Joinville (Tombamento Municipal, Estadual e Federal) Livro Tombo. Coordenação de Patrimônio Cultural: Fundação Cultural de Joinville, Joinville, 2016. Atualizado em julho, 2016.

FICKER, C. História de Joinville: subsídios para a crônica da colônia Dona Francisca. 2a ed. Joinville: Letra D’água, 2008.

FLORES, M. B. R, Oktoberfest: turismo, festa e cultura na estação do chopp. Coleção Teses volume III. Florianópolis: Livraria e Editora Obra Jurídica Ltda., 1997.

GUEDES, S. P. L. D. C. História de (i)migrantes: o cotidiano de uma cidade. Joinville: Univille, 2005.

JOINVILLE, P. D. Lei Complementar $n^{o}$ 363, de 19 de dezembro de 2011. Joinville. 2011.

JOINVILLE, P. D. Lei $n^{\circ} 1.772$, de 25 de novembro de 1980. Joinville. Altera o art. 17 da Lei $\mathrm{n}^{\circ} 1514$, de 27 de maio de 1977, criando a COMPHAAN.

JOINVILLE, P. D. Lei $n^{o} 1.773$, de 10 de dezembro de 1980. Joinville. Dispõe sobre a proteção do patrimônio histórico, arqueológico, artístico e natural do município de Joinville.

NIEHUES, V. D. De agricultor a operário: lembranças de migrantes. Dissertação de Mestrado em História, Florianópolis, 2000. 245 p.

VELHO, G. Observando o familiar. In: NUNES, E. de O. (Org.). A aventura sociológica: objetividade, paixão, improviso e método na pesquisa social. Rio de Janeiro: Zahar, 1978. p. 36-47.

\section{Entrevistas:}

TANNUS, Naim Andrade. Naim Andrade Tannus: entrevista [23 jun. 2016]. Entrevistadora: Christiane Heloisa Kalb. Joinville: PGM/Prefeitura Municipal de Joinville, 2016. Entrevista concedida ao Projeto de Pesquisa - Tese de Doutorado do Programa Interdisciplinar em Ciências Humanas, da Universidade Federal de Santa Catarina - UFSC. A entrevista na íntegra encontra-se transcrita no arquivo pessoal da pesquisadora.

SILVA, Bruno da. Bruno da Silva: entrevista [24 mar., 15 abr. 2016]. Entrevistadora: Christiane Heloisa Kalb. Joinville: FCJ - CPC - Coordenação do Patrimônio Cultural, 2016. Entrevista concedida ao Projeto de Pesquisa - Tese de Doutorado do Programa Interdisciplinar em Ciências Humanas, da Universidade Federal de Santa Catarina - UFSC. A entrevista na íntegra encontra-se transcrita no arquivo pessoal da pesquisadora. 